\title{
Asymptomatic Bacteriuria among Pregnant Women Attending Tertiary Care Hospital in Lucknow, India
}

\author{
Naimshree Sonkar ${ }^{a}$ Malay Banerjee ${ }^{a}$ Suman Gupta ${ }^{b} \quad$ Absar Ahmad $^{c}$ \\ aDepartment of Microbiology, Career Institute of Medical Sciences and Hospital, Lucknow, India; \\ ${ }^{b}$ Department of Obstetrics and Gynecology, Career Institute of Medical Sciences and Hospital, Lucknow, India; \\ 'Department of Community Medicine, Career Institute of Medical Sciences and Hospital, Lucknow, India
}

\section{Keywords}

Asymptomatic bacteriuria - Antimicrobial susceptibility ·

Semi-quantitative culture · Pregnancy · Screening

\begin{abstract}
Introduction: Asymptomatic bacteriuria (ASB) is the presence of actively multiplying bacteria within the urinary tract with absence of any symptoms, resulting in adverse pregnancy outcomes. This research study was done in order to review prevalence, antimicrobial susceptibility profile, and factors associated with ASB occurring in female patients who are pregnant and being treated at a tertiary care hospital in Lucknow, India. Method and Materials: This is a cross-sectional study done among 216 pregnant women attending a hospital for antenatal check-ups. Clean catch midstream urine samples were collected and examined microscopically, and semi-quantitative culture was done on blood agar and MacConkey agar. Isolates were identified by colony morphology and biochemical tests, and antimicrobial susceptibility testing was done by using the Kirby-Bauer method. $\boldsymbol{R e}$ sults: Of the 216 pregnant women, 36 (16.7\%) tested positive for ASB. The female gestational period, haemoglobin
\end{abstract}

level, and BMI were significantly associated with ASB. Logistic regression also showed that higher haemoglobin level was less likely to $A S B$ (AOR $=0.42,95 \%$ confidence interval: $0.202-0.88, p=0.021)$. The predominant and usual isolates were E. coli $(n=22,61.1 \%)$, followed by Cons $(n=6,16.7 \%)$, and S. aureus (3, 8.3\%). All Gram-negative isolates were mostly sensitive to most of the drugs like piperacillin-tazobactam, cefepime, nitrofurantoin, and meropenem but were 100\% resistant to ampicillin. Similarly, Gram-positive isolates were sensitive to ampicillin, vancomycin, linezolid, and nitrofurantoin but $100 \%$ resistant to co-trimoxazole. Conclusion: The present study shows the existence of ASB was $16.7 \%$ among women who are pregnant. Pregnancy duration, haemoglobin level, and BMI were significantly associated with ASB. The isolates identified more frequently were $E$. coli $(61.16 \%)$, Cons (16.7\%), and S. aureus (8.3\%). All isolates which were Gram-negative were mostly sensitive to most of the drugs but were $100 \%$ resistant to ampicillin. Similarly, Gram-positive isolates were sensitive to most of the drugs but $100 \%$ resistant to co-trimoxazole.

(c) 2021 The Author(s)

Published by S. Karger AG, Basel karger@karger.com www.karger.com/dmj

Karger ${ }^{\prime \prime}$

BOPEN ACCESS
C) 2021 The Author(s)

Published by S. Karger AG, Basel

This article is licensed under the Creative Commons AttributionNonCommercial-NoDerivatives 4.0 International License (CC BYNC-ND) (http://www.karger.com/Services/OpenAccessLicense) Usage and distribution for commercial purposes as well as any distribution of modified material requires written permission.
Absar Ahmad

Department of Community Medicine,

Manipal Tata Medical College Kadani Road Baridih Jamshedpur Jharkhand 831017 (India)

r.absar.ahmad@gmail.com 


\section{Introduction}

Asymptomatic bacteriuria (ABS) is the existence of bacteria when urine of a person with no symptoms of a urinary tract infection (UTI) is collected [1]. It is also defined as the existence of bacteria that are actively multiplying and $>10^{5}$ cfu per $\mathrm{mL}$ of urine within the urinary tract, excluding the urethra, when the patient does not have any symptoms of a UTI [2]. Although few infants and toddlers have ASB [1], women are at high risk compared to men, and risks increase with age [3]. Most patients who are diagnosed with ASB may not develop symptomatic UTIs and not have adverse consequences [4]. But pregnant women undergo anatomical and physiological changes in the urinary tract, and their immune system too undergoes changes during pregnancy, resulting in an increase in the risk of ASB [5]. In about $70 \%$ of the cases, ASB is a major risk factor for the occurrence of UTIs in women while they are pregnant [6].

During pregnancy, ASB increases the possibility of the case progressing to UTI with symptoms, which may further lead to pyelonephritis and obstetric outcomes that are adverse in nature and may result in premature delivery, low weight at birth, and increased foetal mortality [7]. In addition, pre-eclamptic toxaemia, anaemia, intrauterine growth retardation, preterm labour, preterm premature rupture of the membrane, and post-partum endometritis [8] may also occur due to ASB. There is sufficient evidence suggesting that a pregnant woman with ASB should be treated $[4,9,10]$. Researchers suggest a regular culture screening for all pregnant women presenting themselves to antenatal clinics due to the adverse effects of undiagnosed ASB in the mother and child [5, 11] and also to prevent the mother and newborn child from any further complications likely to occur due to infection. Culturing still is the best standard screening technique for identifying ASB [7]. However, in many countries including India and other developing countries, it is uncommon to conduct a routine urine culture test for antenatal patients [12]. The primary reason for this practice being the time factor for culture results and the cost involved (usually a period of $48 \mathrm{~h}$ is needed for culture result), it is instead normal practice to go for the strip urinalysis for finding the presence of glucose and protein content [13].

Globally, the existence of ASB has been reported to be between $2-10 \%$ [14]. But various studies show prevalence higher than this, such as $25.3 \%$ in Odisha [15], $17 \%$ in Andhra Pradesh [16], 17\% in Lucknow [8], and 23.9\% in Nigeria [17].

Asymptomatic Bacteriuria among

Pregnant Women
Pyuria is one of the urinary tract conditions that are common during pregnancy, and it is considered when the midstream urine specimen has 5 and more WBC count occurring per cubic millimetre [18]. According to studies based on the population record, this is a predominantly existing condition and is found that $13.9 \%$ of women and $2.6 \%$ of men are being affected [19].

In the current health scenario, unnecessary antibiotics are discouraged, and a vital clinical question in this regard is which ASB patients benefit from antibiotic treatment? A direct answer to this question is that patients with ASB do not require any treatment in most cases; however, few exceptions are there, such as in women who are pregnant. There is enough research to evidence that a pregnant woman must be treated for ASB [4].

In spite of an association of ASB with adverse pregnancy results, screening and treatment is not done with much strength [20]. Mostly, the literature in India suggests existence of ASB and antibiotic vulnerability patterns in respondents in various health centres $[2,7,8]$. It is found that such data are not present in the area that is being studied, and the antibiotic susceptibility patterns differ from region to region and in different global locations and are found to vary from time to time. Thus, the current study will add significant knowledge to the existing literature. Therefore, this study primarily focuses on assessing the existence, antimicrobial susceptibility profile, and related factors of ASB among pregnant women in a tertiary care hospital in Lucknow.

\section{Materials and Methods}

\section{Study Design}

A cross-sectional study was done at the Career Institute of Medical Sciences and Hospital, Lucknow, between April and December 2019. The present study was part of a doctor of medicine program of the author NS in the Department of Microbiology at the Career Institute of Medical Sciences and Hospital. It is a tertiary care hospital located around $12 \mathrm{kM}$ from Lucknow city. It is a private-run hospital, which charges nominal, with a catchment population of more than 20 villages.

Study settings: This study was carried out in Lucknow, Uttar Pradesh state of India. The state has the largest population in the country, with approximately 200 million people. Lucknow is the capital and has an estimated population of about 4.6 million according to census 2011 , and $33.8 \%$ of the people live in rural areas. The district's literacy rate is $77 \%$, and for the rural area, it is $67.8 \%$ [21].

\section{Study Participants}

This study was carried out by the Department of Microbiology with the help of the Department of Obstetrics and Gynaecology at the Career Institute of Medical Sciences and Hospital, Lucknow, 
India. Respondents for this study were women who were pregnant and came to the antenatal clinic at the medical college.

Participant eligibility criterion: Participants of this research were women who were pregnant and aged 18-45 years, having no symptoms of UTI, with singleton pregnancy, with no haemorrhage, and with preterm labour in the previous pregnancy. Women were excluded in case they were using antibiotics in the preceding 2 weeks of their coming to the antenatal clinic, suffering from chronic illness or recurrent abortions.

\section{Sample Size Estimation}

The sample size of the study was determined by using the formula $Z^{2} p q / d^{2}$ (where " $p$ " is the prevalence of ASB observed in the research conducted by Jain et al. [8], $Z$ is the type 1 error at 5 percent, and $d$ is the margin of error). Therefore, based on sample size calculations ( $p=0.17, Z=1.96, d=0.05)$, the requisite size of the sample was 216 .

Selection of the participants of the study: The researchers used non-random sampling to select respondents who were to be included in the study. Women coming to attend the antenatal clinic were chosen for initial screening so that they could be included in the study on a daily basis. Being a student of doctor of medicine with shortage of time, daily 3-4 women were chosen for screening. In cases where the selected participant was found not to be eligible for being included in the study, the next selection replaced her. This practice was followed until the required sample size was realized. The researcher checked selected women for eligibility in the process as mentioned above. The chosen participants were given orientation about the researcher's study before being considered.

Method of specimen collection and transport: About $20 \mathrm{~mL}$ of midstream clean catch urine samples were obtained from recruited women in sterile universal containers, attending the obstetric OPD of the Career Institute of Medical Sciences and Hospital, Lucknow. Samples thus collected were immediately transported to the diagnostic microbiology department without delay; if a delay was suspected, then it was refrigerated at $4^{\circ} \mathrm{C}$.

\section{Screening Procedures}

The presence of pus cells, RBCs, epithelial cells, and casts were identified from uncentrifuged urine samples that were processed microscopically. Pus cells that were greater than 5 per high-power field were recorded under pyuria. They were then immediately cultured semi-quantitatively on dried plates of blood agar and MacConkey agar, using a calibrated loop. Plates were aerobically incubated at $37^{\circ} \mathrm{C}$ overnight. Colony counts yielding bacterial growth of $10^{5}$ per $\mathrm{mL}$ or more of pure isolates were regarded as noteworthy for infection. The isolates were further processed for identification by standardised laboratory technique [16]. Antimicrobial in vitro susceptibility testing was done using the Kirby-Bauer disc diffusion test with $0.5 \mathrm{McF}$ arland standard turbidity of the inoculum on Muller-Hinton agar [22]. The zone diameter of the isolates tested against the selected antibiotics in accordance with the Clinical Laboratory Standard Institute guidelines [23] was measured.

\section{Statistical Analysis}

Collected data were first entered into an Excel sheet and later exported to IBM SPSS 25 for the purpose of analysis. The existence of ASB was calculated as proportion. This was done by dividing the number of cultures that are positive by the total size of the sample taken. $\chi^{2}$ and $t$ tests were used to determine the association and
Table 1. Socio-demographic and clinical profile of pregnant women who attended antenatal care at a tertiary care hospital in Lucknow, India

\begin{tabular}{lr}
\hline Variable & Summary measures \\
\hline Age, years, mean (SD) & $25.96(4.43)$ \\
Residence, $n(\%)$ & $153(70.8)$ \\
$\quad$ Rural & $63(29.2)$ \\
Urban & \\
Religion, $n$ (\%) & $166(76.9)$ \\
$\quad$ Hindu & $50(23.1)$ \\
Muslim & \\
Gestational period, $n(\%)$ & $29(13.4)$ \\
$\quad$ st & $111(51.4)$ \\
2nd & $76(35.2)$ \\
3rd & $24.19(2.53)$ \\
BMI kg/m ${ }^{2}$, mean (SD) & $1.1(1.06)$ \\
Children, $n$, mean (SD) & \\
Parity, $n(\%)$ & $82(38.0)$ \\
Primi & $134(62.0)$ \\
Multi & \\
Pyuria, $n(\%)$ & $202(93.5)$ \\
No pyuria & $14(6.5)$ \\
Pyuria & \\
ASB, $n(\%)$ & $180(83.3)$ \\
No & $36(16.7)$ \\
Yes & \\
\hline
\end{tabular}

ASB, asymptomatic bacteriuria.

mean differences. In order to establish factors associated with ASB, logistic regression analysis was used. Odds ratio and 95\% confidence interval (CI) were calculated to estimate the strength of the association. A $p<0.05$ was considered statistically significant.

\section{Results}

The socio-demographic attributes of the 216 participants are displayed in Table 1 . The average age of the women was $26(\mathrm{SD}=4.43)$ years; they were residents of rural areas $(70.8 \%)$ and were Hindus (77\%). Most of the participants were in the second trimester, and the mean haemoglobin level and BMI were $10.03 \mathrm{~g} / \mathrm{dL}$ and 24.19 $\mathrm{kg} / \mathrm{m}^{2}$, respectively. The average number of children was 1 , and $62 \%$ of participants were multigravida. Thirty-six (16.7\%) of the 216 participants recruited had ASB. Table 2 shows the bivariate relation of the exposure variable with ASB. The gestational period, haemoglobin level, $\mathrm{BMI}$, and presence of pyuria were significantly associated with ASB. In bivariate logistic regression (Table 3), pregnant women who had higher haemoglobin level were 0.58 
Table 2. Socio-demographic and clinical factors among pregnant women who attended antenatal care at a tertiary care hospital in Lucknow, India

\begin{tabular}{|c|c|c|c|}
\hline Variable & ASB & No ASB & $p$ value \\
\hline Age, years, mean (SD) & $25.74(4.38)$ & $27.03(4.57)$ & $0.113(\mathrm{~ns})^{\#}$ \\
\hline \multicolumn{4}{|l|}{ Residence, $n(\%)$} \\
\hline Rural & $28(18.3)$ & $125(81.7)$ & \multirow[t]{2}{*}{$0.315(\mathrm{~ns})^{*}$} \\
\hline Urban & $8(12.7)$ & $55(87.3)$ & \\
\hline \multicolumn{4}{|l|}{ Religion, $n(\%)$} \\
\hline Hindu & $28(16.9)$ & $138(83.1)$ & \multirow[t]{2}{*}{$0.885(\mathrm{~ns})^{*}$} \\
\hline Muslim & $8(16.0)$ & $42(84.0)$ & \\
\hline \multicolumn{4}{|l|}{ Gestational period, $n(\%)$} \\
\hline $1 \mathrm{st}$ & $2(6.9)$ & $27(93.1)$ & \multirow[t]{3}{*}{$0.037(\mathrm{~s})^{*}$} \\
\hline 2nd & $15(13.5)$ & $96(86.5)$ & \\
\hline $3 \mathrm{rd}$ & $19(25.0)$ & $57(75.0)$ & \\
\hline Haemoglobin, g/dL, mean (SD) & $9.61(0.78)$ & $10.11(0.94)$ & $0.003(\mathrm{~s})^{\#}$ \\
\hline $\mathrm{BMI}, \mathrm{kg} / \mathrm{m}^{2}$, mean $(\mathrm{SD})$ & $25.04(2.76)$ & $24.01(2.46)$ & $0.026(s)^{\#}$ \\
\hline Children, $n$, mean (SD) & $1.36(1.12)$ & $1.04(1.05)$ & $0.104(\mathrm{~ns})^{\#}$ \\
\hline \multicolumn{4}{|l|}{ Parity, $n(\%)$} \\
\hline Primi & $11(13.4)$ & $71(86.6)$ & \\
\hline Multi & $25(18.7)$ & $109(81.3)$ & $0.136(\mathrm{~ns})^{*}$ \\
\hline \multicolumn{4}{|l|}{ Pyuria, $n(\%)$} \\
\hline No & $28(13.9)$ & $174(86.1)$ & \\
\hline Yes & $8(57.1)$ & $6(42.9)$ & $0.000(\mathrm{~s})^{*}$ \\
\hline
\end{tabular}

$\mathrm{s}$, significant; ns, non-significant; ASB, asymptomatic bacteriuria. ${ }^{*} \chi^{2}$ test. $^{*} \mathrm{t}$ test.

times less likely (or 0.42 times likely) to develop ASB than those whose haemoglobin level was 1 unit $(\mathrm{g} / \mathrm{dL})$ lower $(\mathrm{AOR}=0.42,95 \% \mathrm{CI} 0.202-0.88, p=0.021)$; ASB was also more likely to occur in the presence of pyuria.

The common organism isolated was E. coli at $61.1 \%$ $(22 / 36)$, followed by Cons $16.7 \%$ (6/36), as shown in Table 4 . Further, Table 5 displays the antimicrobial susceptibility profile of the isolates in detail. In the current study, Gram-positive isolates were found to be $100 \%$ sensitive to ampicillin, piperacillin-tazobactam, vancomycin, linezolid, cefepime, teicoplanin, and nitrofurantoin. However, they were found to be $100 \%$ resistant to co-trimoxazole. Alternatively, Gram-negative isolates were relatively found to be $100 \%$ sensitive to piperacillin-tazobactam, cefepime, nitrofurantoin, meropenem, tigecycline, minocycline, and colistin, and in contrast, they were found to have resistance to ampicillin (100\%).

\section{Discussion/Conclusion}

The first step towards ensuring health of mothers and newborns is through proper antenatal care services [24]. However, the basic elements of antenatal care are present for a long time in the Indian health system, yet progress
Table 3. Logistic regression analysis of factors associated with ASB among pregnant women receiving antenatal care at a tertiary care hospital in Lucknow, India

\begin{tabular}{lll}
\hline Variable & Adjusted OR (95\% CI) & $p$ value \\
\hline $\begin{array}{l}\text { Age, years } \\
\text { Residence }\end{array} \quad$ 1.017 (0.906-1.141) & 0.780 \\
$\quad$ Rural & Ref & 0.472 \\
$\quad$ Urban & $0.699(0.263-1.855)$ & \\
Religion & & \\
$\quad$ Hindu & Ref & 0.585 \\
$\quad$ Muslim & $0.762(0.288-2.018)$ & \\
Trimester & & \\
$\quad$ 1st & Ref & 0.768 \\
2nd & $0.572(0.083-3.922)$ & 0.569 \\
$\quad$ 3rd & $0.716(0.083-6.159)$ & 0.761 \\
Haemoglobin, g/dL & $0.421(0.202-0.88)$ & $0.021^{*}$ \\
BMI, kg/m ${ }^{2}$ & $1.181(0.967-1.442)$ & 0.104 \\
Children, $n$ & $0.932(0.555-1.564)$ & 0.790 \\
Pyuria & & \\
$\quad$ No & Ref & $0.000^{*}$ \\
$\quad$ Yes & $11.635(3.378-40.074)$ & \\
\hline
\end{tabular}

Ref, reference category; OR, odds ratio; CI, confidence interval; ASB, asymptomatic bacteriuria. *Significant at 5\% level of significance. 
is meagre [25]. About $51 \%$ of the female patients had at least 4 ANC visits during their pregnancy, but seventeen percent of the women had no ANC visits. As per the National Family Health Survey, women from urban areas are more likely to have $>4$ ANC visits than rural women [26]. Nevertheless, it is found that a routine urine culture test is not conducted in pregnant women for ASB screening at the time of the ANC visit. On the other hand, urine strip tests were conducted for urinalysis. Further empirical basis alone is used for treatment [12]. Thus, an early detection and treatment of ASB is of considerable importance to obviate foetal and maternal complication [2].

In the current study, the existence of ASB in women who are pregnant stood at $16.7 \%$. The researchers observed that the prevalence of ASB varied in various studies. The findings from this research found $8 \%$ prevalence in India as per different studies [2, 7, 27, 28], Uganda $3.75 \%$ [29], Bangladesh 12\% [6], Iran 8.9\% [30], and Ethiopia 15.6\% [31]. This study found results are congruent with other reports from India, which also reported ASB prevalence between 16 and $17 \%$ [8]. Further, the findings of this research found the prevalence to be lower than that of other studies in India (25.3\%) [15], Ethiopia (21.2\%) [3], and Nigeria (29.5\%) [20]. The different levels of ASB across different states within the country and different countries might be due to the differences in related factors, such as the sample size, geographical differences, social habits prevalent in the community, and the healthrelated practices [3]. The most common bacterial isolate was $E$. coli as per this study, and similar results were also reported in India [2] and in other countries [3, 29]. Numerous investigations indicate that uropathogenic E. coli possesses virulence factors that enhance their ability to colonize and invade the urinary tract [32].

Bivariate analysis shows the gestational period was significantly associated with ASB $(p<0.05)$, more often in the third trimester. Similar findings were also found in the study done in Ethiopia [3]. This perhaps is due to the fact that UTI/ASB in women who are pregnant normally starts within the 6 th week and usually peaks by the $22 \mathrm{nd}-$ 24th week primarily due to urethral dilation, an increased volume of the bladder at the same time reduced bladder tone accompanied with decreased urethral tone. This encourages bacterial growth in urine. It is also specified that the good practice for screening ASB is in the 12th-16th week of pregnancy [33]. However, our study does not find association in multivariable analysis. It may be because of insufficient sample. Previously, a study also reported non-association between the gestational period and ASB [13].
Table 4. Bacteriologic isolates from urine samples of pregnant women with ASB receiving a tertiary care hospital in Lucknow, India

\begin{tabular}{ll}
\hline Type of bacteriologic isolate & $N(\%)$ \\
\hline Gram-positive organisms & \\
$\quad$ Cons & $6(16.7)$ \\
$\quad$ Enterococcus & $1(2.8)$ \\
S. aureus & $3(8.3)$ \\
Gram-negative organism & \\
$\quad$ Klebsiella & $2(5.6)$ \\
Proteus & $1(2.8)$ \\
Pseudomonas & $1(2.8)$ \\
$\quad$ E. coli & $22(61.1)$ \\
Total & $36(100)$ \\
\hline
\end{tabular}

ASB, asymptomatic bacteriuria.

In this study, bivariate and multivariable analyses revealed that the occurrence of ASB is associated with the haemoglobin level. Pregnant women having a higher haemoglobin level were found less than half times (AOR = 0.42 , 95\% CI $0.202-0.88, p=0.021$ ) likely to be positive for ASB. This is in line with the findings in another research that was done in Ethiopia [31, 34] and Iran [30]. Study done by Cuttitta et al. [35] also found the deficiency of iron is a predominant and vital risk factor for ASB. This may be explained by the fact that individuals with conditions of iron deficiency perhaps are more likely to acquire different types of infections than those who are with a normal iron level [36]. India has the largest number of anaemic pregnant women in the world as prevalence of anaemia in pregnancy is the highest $[37,38]$. Many recent studies have also shown that anaemia is still a major health issue in many developing countries and is associated with increased maternal and perinatal mortalities, low birth weight, premature delivery, and other undesirable outcomes [39].

The present study also found bivariate association between BMI and ASB. Similar findings were found by Geerlings et al. [40] and Cuttitta et al. [35] where ASB was independently associated with BMI $[35,40]$. According to Takeda et al. [41], sympathetic hyperactivity in obese people can increase prostate volume, voiding dysfunction, and ultimately the occurrence of UTI. Sterile pyuria is an insidious condition both in primary and secondary care establishments, but limited studies are done to support estimated existence in the community or hospitals [42]. In the present study, prevalence of pyuria was $6.5 \%$ 


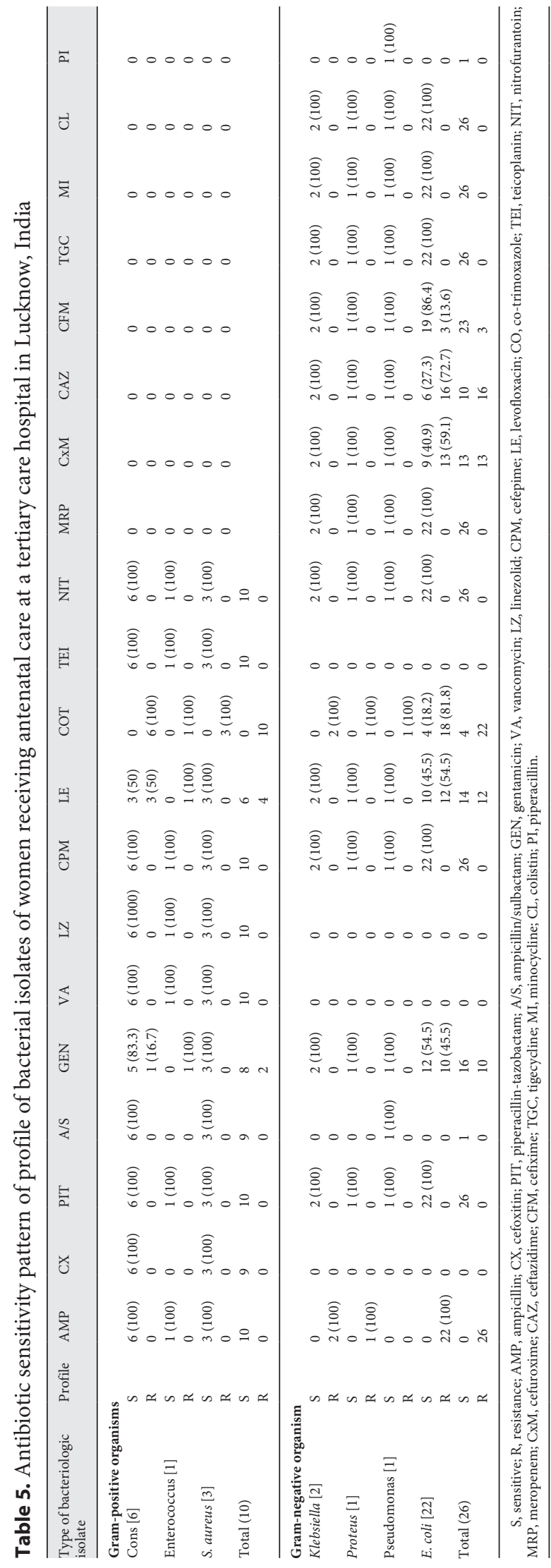

Asymptomatic Bacteriuria among Pregnant Women and was found to be significant with ASB. Similar finding was also found in a study done in northern Ghana [42].

The major isolates that are identified in the current study are Gram-negative bacteria, particularly E. coli. This is a similar finding as in some studies in India [2], Iran [5], and Ethiopia [3]. With respect to the antimicrobial resistance profile of the isolates, this research found that Gram-negative isolates were displaying a greater resistance to the commonly prescribed antibiotics in the country [3]. Further Gram-negative isolates were found relatively $100 \%$ sensitive to piperacillin-tazobactam, cefepime, nitrofurantoin, meropenem, tigecycline, minocycline, and colistin and found to be resistant to ampicillin (100\%), in contrast. Similar studies in Ethiopia and other countries have also reported findings that are majorly comparable [3]. Alternatively, Gram-positive isolates were found $100 \%$ sensitive to ampicillin, piperacillintazobactam, vancomycin, linezolid, cefepime, teicoplanin, and nitrofurantoin. However, they were found $100 \%$ resistant to co-trimoxazole.

In the current study, there are certain limitations such as the researcher collected urine sample only one time irrespective of the participants' period of gestation, which is likely to have a potential impact on the actual status of ASB extending throughout the entire pregnancy duration. Another limitation is lack of data on extended-spectrum beta-lactamase production status of some samples, which is mainly attributed to resource limitations.

\section{Conclusion}

The present study shows the existence of ASB was $16.7 \%$ among women who are pregnant. Pregnancy duration, haemoglobin level, and BMI were significantly associated with ASB. Logistic regression also showed that a higher haemoglobin level was less likely to ASB. The isolates which were identified more frequently were $E$. coli $(61.16 \%)$ and Cons (16.7\%), followed by S. aureus (8.3\%). All isolates which were Gram-negative were mostly sensitive to most of the drugs but were $100 \%$ resistant to ampicillin. Similarly, Gram-positive isolates were sensitive to most of the drugs but $100 \%$ resistant to co-trimoxazole. Therefore, for women who are pregnant, in the first and second trimesters of their pregnancy, need screening and treatment for ASB, and this should be adopted in practice of antenatal care. A time-based observation of the type of bacterial pathogens and the profile of their updated antimicrobial resistance in the area under study is further needed. 


\section{Acknowledgements}

The authors would like to thank Amita Arya, Manjusha Pandey, and Priya Chauhan (Department of Microbiology), Career Institute of Medical Sciences and Hospital, for their kind support during the course.

\section{Statement of Ethics}

This study was approved by the Student Ethics Committee of the Career Institute of Medical Sciences and Hospital of Lucknow held on Feb 26, 2019 (Ref Number CIMS/MB/2019/1521 dated July 09, 2019). Prior to collecting data, the formal consent of the participants was received in the respondent's own language; for respondents who were not literate, the interviewer read the statement of consent. The statement of consent identified the researcher as well as the purpose of study. The participation of the respondents was voluntary, and they could leave if they wanted to. Further, the privacy and confidentiality of all information received was maintained.

\section{Conflict of Interest Statement}

There are no conflicts of interest.

\section{Funding Sources}

This research did not receive any specific grant from funding agencies in the public, commercial, or not-for-profit sectors.

\section{Author Contributions}

N.S., M.B., S.G., and A.A. designed the work. N.S. collected the data. A.A. contributed to the statistical analysis. All authors contributed to draft the article and final approval of the version to be submitted.

\section{References}

1 Givler DN, Amy G. Asymptomatic bacteriuria. In: StatPearls [Internet]. Treasure Island. StatPearls Publishing; 2020. Available from: https://www.ncbi.nlm.nih.gov/books/ NBK441848/.

2 Jayalakshmi J, Jayaram VS. Evaluation of various screening tests to detect asymptomatic bacteriuria in pregnant women. Indian J Pathol Microbiol. 2008;51(3):379-81.

3 Tadesse S, Kahsay T, Adhanom G, Kahsu G, Legese H, G/Wahid A, et al. Correction to: prevalence, antimicrobial susceptibility profile and predictors of asymptomatic bacteriuria among pregnant women in Adigrat General Hospital, Northern Ethiopia. BMC Res Notes. 2018 Oct 19;11(1):798.

4 Ditkoff EL, Theofanides M, Aisen CM, Kowalik CG, Cohn JA, Sui W, et al. Assessment of practices in screening and treating women with bacteriuria. Can J Urol. 2018 Oct;25(5):9486-96.

5 Azami M, Jaafari Z, Masoumi M, Shohani M, Badfar G, Mahmudi L, et al. The etiology and prevalence of urinary tract infection and asymptomatic bacteriuria in pregnant women in Iran: asystematic review and meta-analysis. BMC Urol. 2019;19(1):1-15.

6 Ullah MA, Barman A, Siddique MA, Haque AK. Prevalence of asymptomatic bacteriuria and its consequences in pregnancy in a rural community of Bangladesh. Bangladesh Med Res Counc Bull. 2007 Aug;33(2):60-4.

7 Sujatha R, Nawani M. Prevalence of asymptomatic bacteriuria and its antibacterial susceptibility pattern among pregnant women attending the antenatal clinic at Kanpur, India. J Clin Diagnostic Res. 2014;8(4):2-4.

8 Jain V, Das V, Agarwal A, Pandey A. Asymptomatic bacteriuria \& obstetric outcome fol- lowing treatment in early versus late pregnancy in north Indian women. Indian J Med Res. 2013;137(4):753-8.

9 Wullt B, Sundén F, Grabe M. Asymptomatic bacteriuria is harmless and even protective: don't treat if you don't have a very specific reason. Eur Urol Focus. 2019 Jan;5(1):15-6.

10 Averbeck MA, Rantell A, Ford A, KirschnerHermanns R, Khullar V, Wagg A, et al. Current controversies in urinary tract infections: ICI-RS 2017. Neurourol Urodyn. 2018 Jun; 37(S4):S86-92.

11 Moore A, Doull M, Grad R, Groulx S, Pottie $\mathrm{K}$, Tonelli $\mathrm{M}$, et al. Recommendations on screening for asymptomatic bacteriuria in pregnancy. CMAJ. 2018;190(27):E823-30.

12 Singh L, Dubey R, Singh S, Goel R, Nair S, Singh P. Measuring quality of antenatal care: a secondary analysis of national survey data from India. BJOG: Int J Obstet Gy. 2019; 126(S4):7-13.

13 Imade PE, Izekor PE, Eghafona NO, Enabulele OI, Ophori E. Asymptomatic bacteriuria among pregnant women. N Am J Med Sci. 2010;2(6):263-6.

14 Delzell JE, Lefevre ML. Urinary tract infections during pregnancy. Am Fam Physician. 2000 Feb;61(3):713-21.

15 Patnaik M, Panigrahi K, Das B, Pathi B, Poddar N, Lenka PR, et al. Asymptomatic bacteriuria in pregnancy: prevalence, risk factors and causative organisms. Int J Adv Med. 2017; 4(5):1348-54

16 Prasanna B, Naimisha M, Swathi K, Shaik MV. Prevalence of asymptomatic bacteriuria in pregnant women, isolates and their culture sensitivity pattern. Int J Curr Microbiol Appl Sci. 2015;4(8):28-35.
17 Olusanya O, Ogunledun A, Fakoya TA. Asymptomatic significant bacteriuria among pregnant and non-pregnant women in Sagamu, Nigeria. West Afr J Med. 1993;12(1): 27-33. Available from:.http://europepmc. org/abstract/MED/8512878.

18 Wise GJ, Schlegel PN. Sterile pyuria. N Engl J Med. 2015 Mar;372(11):1048-54.

19 Alwall N, Lohi A. A population study on renal and urinary tract diseases. II. Urinary deposits, bacteriuria and ESR on screening and medical examination of selected cases. Acta Med Scand. 1973 Dec;194(6):529-35.

20 Izuchukwu KE, Oranu EO, Bassey G, Orazulike NC. Maternofetal outcome of asymptomatic bacteriuria among pregnant women in a nigerian teaching hospital. Pan Afr Med J. 2017:27:69-6.

21 Census. Primary Census Abstract Data Tables [Internet]. Ministry of Home Affairs. 2011 [cited 2016 Aug 29]. Available from: http:// censusindia.gov.in/pca/pcadata/Houselisting-housing-RJ.html.

22 Mary Bose A, PKSS. Microbiological profile of asyptomatic bacteriuria in pregnancy. Crit Care Obst \& Gyne. 2016;02(05):1352-61.

$23 \mathrm{Pk}$ PM, James SL II, Bobenchik AM, Campeau S, Cullen SK, Galas MF, et al. Performance standards for antimicrobial susceptibility testing. 30th ed. Pennsylvenia; 2020.

24 Roy MP, Mohan U, Singh SK, Singh VK, Srivastava AK. Determinants of utilization of antenatal care services in rural Lucknow, India. J Family Med Prim Care. 2013;2(1):55.

25 Ali B, Chauhan S. Inequalities in the utilisation of maternal health care in Rural India: evidences from national family health survey III \& IV. BMC Public Health. 2020;20(1):369-13. 
26 IIPS, ICF. National Family Health Survey (NFHS-4), 2015-16: India. Mumbai; 2017.

27 Gayathree L, Shetty S, Deshpande SR, Venkatesha DT. Screening For asymptomatic bacteriuria in pregnancy: an evaluation of various screening tests at the hassan district hospital, India. J Clin Diagnostic Res. 2010;4: 2702-6.

28 Mangalgi S, Sajjan A. Asymptomatic bacteriuria in pregnancy. J Krishna Inst Med Sci Univ. 2018;7(3):35-42.

29 Nteziyaremye J, Iramiot SJ, Nekaka R, Musaba MW, Wandabwa J, Kisegerwa E, et al. Asymptomatic bacteriuria among pregnant women attending antenatal care at Mbale Hospital, Eastern Uganda. PLoS One. 2020; 15(3):1-12.

30 Enayat K, Fariba F, Bahram N. Asymptomatic bacteriuria among pregnant women referred to outpatient clinics in Sanandaj, Iran. Int Braz J Urol. 2008;34(6):699-704.

31 Ali IE, Gebrecherkos T, Gizachew M, Alemayehu Menberu M. Asymptomatic bacteriuria and antimicrobial susceptibility pattern of the isolates among pregnant women attending Dessie referral hospital, Northeast Ethiopia: a hospital-based cross-sectional study. Turkish J Urol. 2018;44(3):251-60.
32 Tille PM. Bailey \& Scott's diagnostic microbiology. 14th ed: Elsevier; 2018.

33 McIsaac W, Carroll JC, Biringer A, Bernstein $\mathrm{P}$, Lyons E, Low DE, et al. Screening for asymptomatic bacteriuria in pregnancy. J Obstet Gynaecol Can. 2005;27(1):20-4.

34 Emiru T, Beyene G, Tsegaye W, Melaku S. Associated risk factors of urinary tract infection among pregnant women at Felege Hiwot Referral Hospital, Bahir Dar, North West Ethiopia. BMC Res Notes. 2013 Jul;6:292.

35 Cuttitta F, Torres D, Vogiatzis D, Buttà C, Bellanca M, Gueli D, et al. Obesity and iron deficiency anemia as risk factors for asymptomatic bacteriuria. Eur J Intern Med. 2014; 25(3):292-5.

36 Tansarli GS, Karageorgopoulos DE, Kapaskelis A, Gkegkes I, Falagas ME. Iron deficiency and susceptibility to infections: evaluation of the clinical evidence. Eur J Clin Microbiol Infect Dis. 2013;32(10):1253-8.

37 Kalaivani K, Ramachandran P. Time trends in prevalence of anaemia in pregnancy. Indian J Med Res. 2018 Mar;147(3):268-77.
38 Stevens GA, Finucane MM, De-Regil LM, Paciorek CJ, Flaxman SR, Branca F, et al. Global, regional, and national trends in haemoglobin concentration and prevalence of total and severe anaemia in children and pregnant and non-pregnant women for 1995-2011: a systematic analysis of population-representative data. Lancet Glob Heal. 2013 Jul;1(1):e16-25.

39 Kozuki N, Lee AC, Katz J. Moderate to severe, but not mild, maternal anemia is associated with increased risk of small-for-gestationalage outcomes. J Nutr. 2012 Feb;142(2):35862.

40 Geerlings SE, Stolk RP, Camps MJ, Netten PM, Collet TJ, Hoepelman AI. Risk factors for symptomatic urinary tract infection in women with diabetes. Diabetes Care. 2000 Dec; 23(12):1737-41.

41 Takeda M, Araki I, Mochizuki T, Nakagomi $\mathrm{H}$, Kobayashi H, Sawada N, et al. The forefront for novel therapeutic agents based on the pathophysiology of lower urinary tract dysfunction: pathophysiology of voiding dysfunction and pharmacological therapy. J Pharmacol Sci. 2010;112(2):121-7.

42 Karikari AB, Saba CKS, Yamik DY. Assessment of asymptomatic bacteriuria and sterile pyuria among antenatal attendants in hospitals in northern Ghana. BMC Pregnancy Childbirth. 2020;20(1):239-7. 